\title{
MÉTODO DE OBTENÇÃO E ANÁLISE DA COMPOSIÇÃO CENTESIMAL DO POLVILHO DA FRUTA-DE -LOBO (Solanum lycocarpum ST. HIL) ${ }^{1}$
}

\author{
DENISE ALVARENGA ROCHA ${ }^{2}$, CELESTE MARIA PATTO DE ABREU ${ }^{3}$, \\ RAIMUNDO VICENTE DE SOUSA ${ }^{4}$, ANGELITA DUARTE CORRÊA
}

RESUMO - O polvilho da fruta-de-lobo é um produto extraído da polpa da fruta-de-lobo verde (Solanum lycocarpum St. Hil), popularmente utilizado. Pouco se conhece a respeito desse polvilho, apesar de ele ser comercializado em farmácias na região de Lavras-MG, na forma de cápsulas de $300 \mathrm{mg}$. É utilizado no tratamento da diabetes e a ele são atribuídos outros efeitos terapêuticos, como a redução da obesidade e do colesterol, mas sem conhecimento científico e sem conhecer sua composição centesimal. Com o objetivo de conhecer sua composição centesimal, foram coletadas 80 frutas-de-lobo na área de pastagem do Departamento de Zootecnia, na Universidade Federal de Lavras. Foram selecionadas 61 frutas, levando em consideração o tamanho e o estádio de maturação. As frutas selecionadas foram lavadas, descascadas e picadas, as sementes retiradas, trituradas e o polvilho obtido foi filtrado, decantado, lavado com água destilada por duas vezes e seco em estufa de ventilação. A amostra foi triturada em um gral de porcelana e armazenada em um recipiente de vidro hermeticamente fechado e protegido da luz, sob temperatura ambiente. Foram realizadas as análises de composição centesimal, observando-se que, no polvilho da fruta-de-lobo, os carboidratos são os constituintes predominantes $(84,99 \%)$, seguidos de fibras solúveis $(1,35 \%)$, fibras insolúveis $(1,60 \%)$, proteínas $(0,60 \%)$, lipídeos $(0,07 \%)$, cinzas $(0,03 \%)$ e umidade $(11,16 \%)$. Os teores de fibras alimentares encontrados no polvilho da fruta-de-lobo podem estar relacionados aos efeitos terapêuticos que são atribuídos a ele.

Termos para indexação: polvilho, fruta-de-lobo, composição centesimal.

\section{OBTAINING METHOD AND ANALYSIS OF THE CENTESIMAL COMPOSITION OF FRUIT-OF-WOLF (Solanum lycocarpum ST. HIL) FLOUR}

\begin{abstract}
Fruit-of-wolf flour is a product extracted from the unripe fruit-of-wolf pulp (Solanum lycocarpum St. Hil), according to folk knowledge. Little is known of that starch; in spite of it is being marketed in pharmacies in the region of Lavras, in $300 \mathrm{mg}$ capsules. It is utilized in the treatment of diabetes and it is also ascribed other therapeutic effects such as reduction of obesity and cholesterol, but without any scientific knowledge and without knowing its centesimal composition. With the objective of knowing its centesimal composition, eighty fruits were collected in the pasture area of the Animal Science Department of the UFLA/Lavras-MG. Sixty-one fruits were selected, taking into account the size and maturation stage. The selected fruits were washed, peeled, chopped, the seeds removed and the obtained starch was filtered, decanted, washed with distilled water twice and dried in an air forced oven. The sample was ground in a china mortar and stored in air-tightly sealed glass container and protected from light at room temperature. The centesimal composition analyses were performed and observing that in the fruit-of-wolf flour, carbohydrates are the predominant constituents $(84.99 \%)$, followed by soluble fibers $(1.35 \%)$, insoluble fibers $(1.60 \%)$, proteins $(0.60 \%)$, lipids $(0.07 \%)$, ashes $(0.03 \%)$ and moisture $(11.16 \%)$. The contents of food fibers found in the fruit-of-wolf flour can be related to the therapeutic effects which are ascribed to it.
\end{abstract}

Index terms: flour, fruit-of-wolf, centesimal composition.

\footnotetext{
${ }^{1}$ (Trabalho 153-11). Recebido em: 16-05-2011. Aceito para publicação em: 19-01-2012.

${ }^{2}$ Farmacêutica, Doutora em Agroquimica/Agrobioquímica pela Universidade Federal de Lavras (UFLA).

${ }^{3}$ Professora associada do Departamento de Química da Universidade Federal de Lavras (UFLA). Bolsista CNPQ Lavras-MG, E-mail: celeste@dqi.ufla.br

${ }^{4}$ Professor titular do Departamento de Medicina Veterinária da Universidade Federal de Lavras(UFLA).

${ }^{5}$ Professora associada do Departamento de Química da Universidade Federal de Lavras (UFLA). Bolsista CNPQ
} 


\section{INTRODUÇÃO}

A lobeira pertence à família Solanaceae, apresenta porte arbustivo e é amplamente distribuída em todo o cerrado brasileiro. A fruta-de-lobo possui forma globosa, ligeiramente achatada, tendo de 8 a 12 cm de diâmetro, coloração verde, quando jovem, podendo atingir peso de até $500 \mathrm{~g}$ (CORRÊA, 1984). A fruta dessa espécie perene pode ser encontrada o ano inteiro, e a planta cresce e desenvolve-se até em condições ambientais desfavoráveis (CAMPOS, 1994). A fruta-de-lobo verde tem polpa firme e, quando amadurece, sua polpa torna-se amarela e macia (HOEHNE, 1946). A fruta-de-lobo é uma espécie comestível e aromática, utilizada na preparação de geleias e doces, e pode também ser misturada aos pêssegos para se fazer a pessegada ou aos marmelos, para a marmelada (CORRÊA, 1984).

$\mathrm{Na}$ fruta-de-lobo podem ser encontrados vários compostos, como água, açúcares (sacarose, glicose e frutose), ânions $\left(\mathrm{Cl}^{1-}, \mathrm{H}_{2} \mathrm{PO}_{4}{ }^{1-} \mathrm{e} \mathrm{HPO}_{4}{ }^{2-}\right.$ ) , cátions $\left(\mathrm{Ca}^{2+}, \mathrm{Mg}^{2+} \mathrm{e} \mathrm{K}^{1+}\right)$, álcoois, ésteres, flavonoides, glicosídeos, fenóis, aminoácidos, vitaminas, alcaloides, terpenos, lipídeos e ácidos orgânicos. Durante a maturação do fruto, o amido é degradado, convertendo-se em açúcares solúveis que contribuem para o sabor adocicado dos frutos maduros (AWAD, 1993).

Oliveira Junior et al. (2003) analisaram alguns nutrientes da fruta-de-lobo, durante o amadurecimento, encontrando vitamina $\mathrm{C}(85 \mathrm{mg})$, açúcares solúveis totais $(11 \mathrm{~g})$, sacarose $(8,6 \mathrm{~g})$, fósforo $(35,5$ $\mathrm{mg})$ e ferro $(1,2 \mathrm{mg})$ em $100 \mathrm{~g}$ de polpa fresca. Os autores observaram que os teores encontrados na fruta-de-lobo, comparados aos de outros frutos, como abacaxi, banana, laranja e manga, entre outros, são equivalentes ou superiores aos dos frutos em questão, concluindo que ela representa mais uma alternativa como fonte nutricional e como alimento funcional, devido ao teor de vitamina $\mathrm{C}$ ser relevante.

Em relação à toxicidade da fruta-de-lobo, Silva et al. (2003) analisaram antinutrientes e não encontraram nitratos nem inibidor de tripsina. Anteriormente, Motta et al. (2002) já haviam empregado o polvilho de lobeira na alimentação de ratas em lactação, não observando nenhum efeito tóxico para as mães nem alteração no desenvolvimento físico das crias.

Têm-se atribuído à fruta-de-lobo propriedades terapêuticas hipoglicemiantes, redução de obesidade, redução do colesterol e atividade anti-inflamatória (DALL-AGNOL; VON-POSER, 2000; VIEIRA JÚNIOR et al., 2003). Do fruto verde, obtém-se polvilho, que é utilizado por pacientes com diabetes mellitus, um distúrbio crônico caracterizado por hiperglicemia (HARDMAN et al., 1996; RANG et al., 2001).

Informações sobre a composição centesimal de alguns fitoterápicos são escassas e, muitas vezes, eles são utilizados pela população de modo empírico, sem nenhuma identificação dos constituintes que possam estar envolvidos na eficácia terapêutica. Como exemplo, pode-se citar a espécie Solanum lycocarpum, conhecida como lobeira e encontrada em todo o território brasileiro.

Considerando a importância de identificar a composição desse polvilho, o presente trabalho foi realizado com o objetivo de desenvolver uma metodologia para obter o polvilho e analisar sua composição centesimal.

\section{MATERIAL E MÉTODOS}

O experimento foi realizado no Câmpus da Universidade Federal de Lavras (UFLA), em Lavras-MG, situada no sul de Minas Gerais, à altitude de $918 \mathrm{~m}$, nas coordenadas latitude $21^{\circ} 14^{2}$ sul e longitude de $45^{\circ} 00^{2}$ oeste (CASTRO NETO et al.,1980). O clima é do tipo subtropical moderado úmido, segundo classificação de Köeppen, tendo duas estações definidas: seca de abril a setembro e chuvosa de outubro a março. A precipitação anual média é de $1.417 \mathrm{~mm}$, com temperaturas máxima e mínima de $22,6^{\circ} \mathrm{C}$ e $15,8^{\circ} \mathrm{C}$, respectivamente (VILELA; RAMALHO, 1980).

Os frutos da espécie vegetal Solanum lycocarpum St. Hil utilizados neste estudo foram coletados na área de pastagem do Departamento de Zootecnia da Universidade Federal de Lavras, para a obtenção do polvilho.

\section{Obtenção do polvilho}

Oitenta frutas-de-lobo foram coletadas no dia $02-04-08$, às $13 \mathrm{~h}$. Destas, foram selecionadas 61, pesando, em média, $350 \mathrm{~g}$ cada e levando-se em consideração o grau de maturação, excluindo-se as frutas maduras e as muito verdes (Figura 1).

As frutas foram pesadas, lavadas com água e, em seguida, descascadas e partidas em uma bacia contendo água destilada. As sementes foram retiradas, e a polpa, picada em pedaços pequenos e pesada. A polpa foi colocada em um liquidificador industrial e batida com água destilada, na proporção de 2:1 (polpa/água destilada), por 2 minutos. A polpa homogeneizada foi filtrada em um tecido de algodão e prensada, para garantir que toda a amostra passasse pelo filtro. O filtrado foi colocado em um béquer e levado a um refrigerador $\left(4^{\circ}-8^{\circ} \mathrm{C}\right)$, por 6 horas, para decantar. 
Após a decantação, o sobrenadante foi desprezado, e o precipitado foi lavado com água destilada e colocado novamente para decantar no refrigerador, por 12 horas. No dia seguinte, a amostra foi lavada e decantada novamente. O sobrenadante foi desprezado e observou-se a formação de uma fração clara no fundo do béquer e outra escura acima desta, que foi desprezada. A fração clara foi colocada em uma bandeja e levada à estufa ventilada, a $30^{\circ} \mathrm{C}$, por três dias. A fração clara e seca foi denominada de polvilho. Este foi triturado, pesado e, em seguida, armazenado em um recipiente de vidro hermeticamente fechado e protegido da luz, sob temperatura ambiente, para análises posteriores.

\section{Análise da composição centesimal}

As determinações da composição centesimal nas amostras foram realizadas em triplicata.

\section{Umidade}

A umidade foi determinada pelo método gravimétrico com o emprego de calor, o qual se baseia na perda de peso do material quando submetido a aquecimento de $105^{\circ} \mathrm{C}$, até atingir peso constante (ASSOCIATION OF OFFICIAL ANALYTICAL CHEMISTS-AOAC, 1995).

\section{Proteína}

A proteína bruta foi determinada pelo método de Kjeldahl, conforme procedimento da AOAC (1995). Após a digestão da amostra com a mistura digestora (sulfato de cobre e sulfato de potássio) e ácido sulfúrico, foi realizada destilação e posterior titulação com solução de ácido clorídrico. Os resultados foram expressos em $\mathrm{g} / 100 \mathrm{~g}$ de polvilho, empregando-se 6,25 como fator de conversão de nitrogênio em proteína.

\section{Extrato etéreo}

Para a obtenção do extrato etéreo, foi utilizado o método de Soxhlet (gravimétrico), baseado na perda de peso do material submetido à extração com éter etílico, ou na quantidade de material solubilizado pelo solvente. Os resultados foram expressos em g/100 g de polvilho (AOAC, 1995).

\section{Cinzas}

O resíduo mineral fixo (cinzas) foi determinado submetendo-se as amostras a $550^{\circ} \mathrm{C}$. Os resultados foram expressos em $\mathrm{g} / 100 \mathrm{~g}$ de polvilho (AOAC, 1995)

\section{Fibra alimentar}

A fibra alimentar total, a fibra alimentar solúvel e a fibra alimentar insolúvel foram determinadas no polvilho da fruta-de-lobo, utilizando-se do kit-dietary fiber total, marca Sigma, seguindo as técnicas propostas pela AOAC (2000), que se baseia nas análises enzimáticas gravimétricas. Esse método baseia-se na porção não hidrolisada do alimento que resiste à digestão enzimática sequencial com a-amilase, protease e amiloglicosidase, e é insolúvel em etanol entre $78 \%$ e $98 \%$. Os resultados foram expressos $\mathrm{g} / 100 \mathrm{~g}$ de polvilho, de acordo com a média das três repetições da amostra.

\section{Carboidratos}

A fração glicídica foi determinada pela diferença dos valores encontrados para umidade, extrato etéreo, proteínas, cinzas e fibras em $100 \mathrm{~g}$ do produto (AOAC, 1995).

\section{RESULTADOS E DISCUSSÃO}

\section{Rendimento do polvilho}

A desidratação das amostras ocorreu após três dias, em estufa ventilada a $30^{\circ} \mathrm{C}$. O rendimento de produção do polvilho a partir da fruta fresca foi de $2,573 \%$ e, a partir da polpa fresca, foi de $4,55 \%$. Foram colhidos $21,180 \mathrm{~kg}$ de frutos verdes, que renderam 544,99 g de polvilho. Grasselli (2001), ao preparar o polvilho da fruta-de-lobo, obteve rendimento de aproximadamente $1 \%$ da fração clara da polpa (polvilho). A diferença encontrada no rendimento do polvilho, a partir da fruta fresca, pode estar relacionada ao método de obtenção da amostra, por não ter sido o mesmo.

\section{Composição centesimal}

$\mathrm{Na}$ Tabela 1, são apresentados os valores médios da composição centesimal do polvilho da fruta-de-lobo.

A umidade encontrada no polvilho da frutade-lobo, no presente trabalho, foi de $11,16 \%$. O valor médio encontrado está próximo do encontrado por Marciano et al. (2001), que relataram valor médio de 14,96\% A pequena diferença de umidade entre os dois trabalhos deve-se, provavelmente, ao método utilizado na secagem da amostra durante o preparo do polvilho da fruta-de-lobo. No presente trabalho, utilizou-se uma estufa ventilada a $30^{\circ} \mathrm{C}$ e, no trabalho daqueles autores, a amostra foi seca ao sol.

Em relação aos lipídeos e cinzas, os valores encontrados foram de $0,07 \%$ e $0,03 \%$, respectivamente. Marciano et al. (2001), ao avaliarem a fração clara do amido da fruta-de-lobo, encontraram $0,08 \%$ de lipídeo e $0,03 \%$ de cinzas, valores próximos dos encontrados neste estudo. A quantidade de lipídeos presente no polvilho não é expressiva, quando comparada à de outros frutos, como banana $(0,6 \%)$, maçã $(0,5 \%)$, pera $(0,5 \%)$ e mamão $(0,2 \%)$ (GOMES, 2007). Os lipídeos exercem importantes funções estruturais e de reserva energética no organismo humano e são essenciais para o crescimento, $\mathrm{o}$ 
desenvolvimento fetal e neonatal, e para as funções neurológicas, comportamental e de aprendizagem (TINOCO, 2007). As cinzas representam os minerais, importantes para a manutenção das funções essenciais ao organismo humano; atuam na rigidez do esqueleto, ossos e em tecidos moles, músculos e, ainda, como cofatores em diversos processos enzimáticos (FRANCO, 2005). O teor médio de cinzas encontrado neste estudo é pequeno quando comparado ao da banana, de $0,8 \%$ (GOMES, 2007).

$\mathrm{O}$ teor de proteína encontrado foi de $0,6 \%$ no polvilho, valor este bem abaixo do encontrado por Oliveira-Jr. et al. (2004) que, estudando alterações dessa fruta durante o amadurecimento, encontraram teor de 3,47\% na polpa da fruta fresca e madura, o que justifica essa diferença. Marciano et al. (2001) encontraram $0,34 \%$ de proteína no polvilho da frutade-lobo. Este valor está mais próximo do encontrado neste estudo, devido ao fato de as amostras estudadas serem as mesmas, ou seja, fração clara e seca da polpa da fruta-de-lobo. As proteínas são moléculas orgânicas que atuam no organismo humano como catalisadores, funções estruturais e enzimáticas, dentre outras funções (NELSON; COX, 2002). A ingestão diária recomendada de proteína/dia para adultos é de 50 gramas, segundo a Agência Nacional de Vigilância Sanitária (ANVISA, 2009). Sendo assim, o polvilho da fruta-de-lobo não é uma boa fonte de proteínas.

Na Tabela 1, encontram-se os valores das fibras solúveis e insolúveis do polvilho da fruta-delobo, que resultam em percentual de fibras totais de $3,15 \%$. Comparando-se este resultado com a fibra total da goiaba inteira, 6,01\% (GIUNTINI et al., 2003), que é considerada apresentar teor razoável de fibras, observa-se que o polvilho da fruta-de-lobo tem uma quantidade significativa, já que o mesmo foi obtido só da polpa. As fibras podem atuar como agentes hipoglicemiantes e hipocolesterolêmicos (FUKAGAMA, 1991; LAJOLO et al., 2001), mantendo a homeostasia da glicose e do colesterol sanguíneo.

O teor de carboidratos no polvilho é de $84,99 \%$. De acordo com os estudos de Rocha (2006), o teor total de amido no polvilho da fruta-de-lobo é de $86,12 \%$, percentual muito próximo do encontrado neste trabalho. A maior parte do polvilho da fruta-delobo é constituída por carboidratos, sendo o amido o constituinte principal. Marciano et al. (2001), analisando o polvilho da lobeira na região de ViçosaMG, encontraram teor de $94,31 \%$ de amido total. Sugere-se, portanto, que a diferença encontrada é, provavelmente, devido aos métodos diferentes de obtenção do polvilho.

Corrêa et al. (2000), estudando o amadurecimento da fruta-de-lobo, encontraram $9,98 \%$ de amido na fruta verde e 3,92\% no final do amadurecimento. $\mathrm{O}$ amido é um polissacarídeo de armazenamento e, a partir de 1980, pesquisas mostraram que uma fração de amido escapa da digestão no intestino delgado e chega ao intestino grosso, servindo de substrato para a flora bacteriana. Esse amido foi denominado de amido resistente (AR) e pode ser definido como a soma do amido ou produto de degradação do amido não absorvido no intestino delgado de indivíduos saudáveis, pois resistem à digestão enzimática no intestino, podendo, entretanto, ser fermentado no intestino grosso (ASP et al., 1994; EERLINGEN; DELCOUR, 1995; FREITAS; TAVARES, 2005). De acordo com Rocha (2006), o polvilho da fruta-de-lobo contém $12,43 \mathrm{mg}$ de AR/100 mg de amido total; esse amido pode estar relacionado com as propriedades hipoglicemiantes e hipocolesterolêmicas desse fitoterápico.

TABELA 1- Composição centesimal de polvilho da fruta-de-lobo obtido no Departamento de Química da UFLA.

\begin{tabular}{ccccccc}
\hline \multicolumn{7}{c}{ Composição centesimal g/100 g de polvilho } \\
\hline Umidade & Cinzas & $\begin{array}{c}\text { Extrato } \\
\text { etéreo }\end{array}$ & Proteína & $\begin{array}{c}\text { Fibra } \\
\text { solúvel }\end{array}$ & $\begin{array}{c}\text { Fibra } \\
\text { insolúvel }\end{array}$ & Carboidratos \\
\hline 11,16 & 0,03 & 0,07 & 0,60 & 1,35 & 1,80 & 84,99 \\
\hline
\end{tabular}



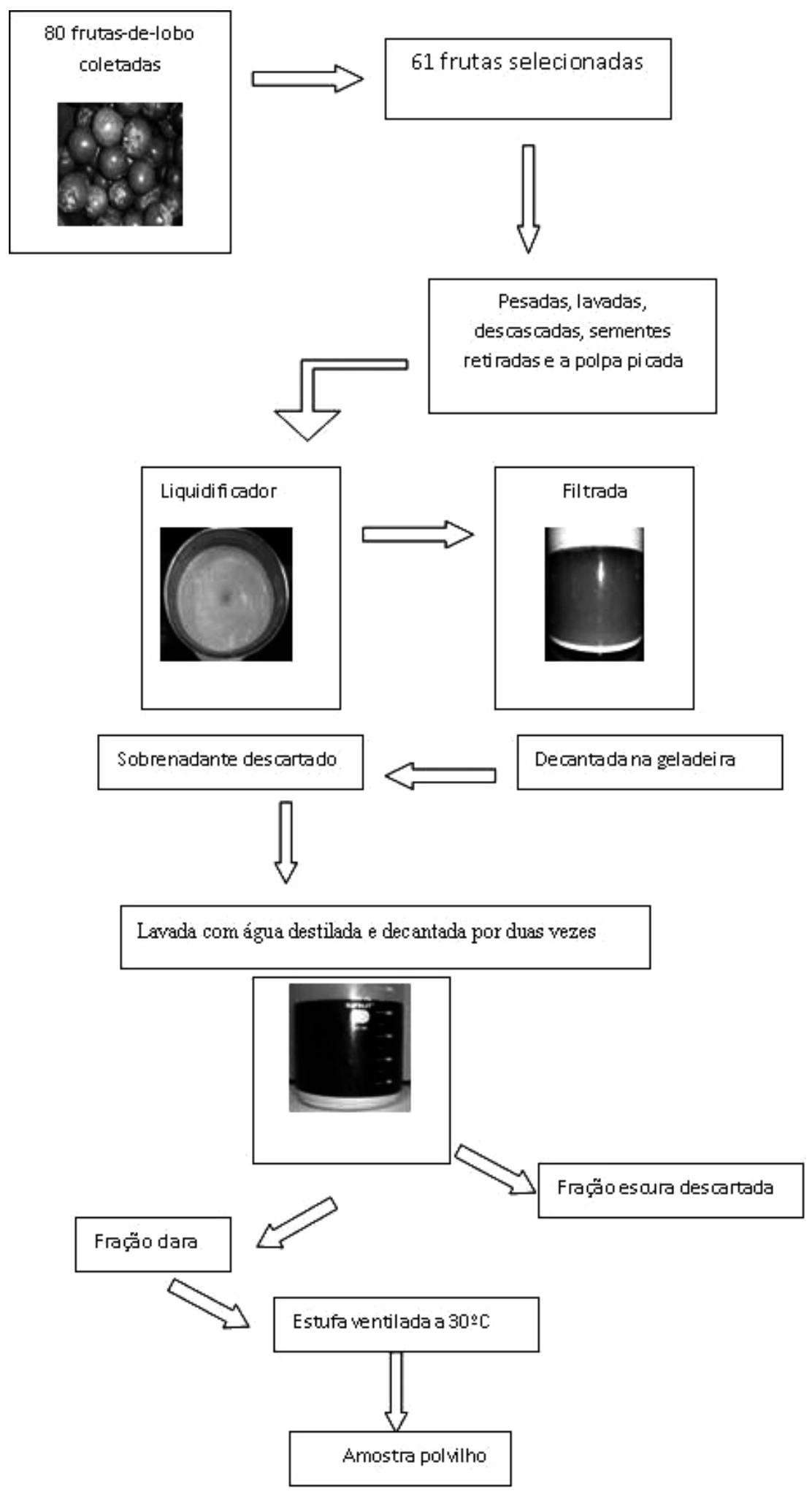

FIGURA 1- Fluxograma do método de obtenção do polvilho da lobeira, realizado no Departamento de Química da UFLA. 


\section{CONCLUSÕES}

No polvilho da fruta-de-lobo, os carboidratos são os constituintes predominantes, e os teores de fibras alimentares encontrados podem estar relacionados aos efeitos terapêuticos que lhe são atribuídos.

\section{AGRADECIMENTOS}

Ao Conselho Nacional de Desenvolvimento Científico e Tecnológico (CNPq), pelo apoio financeiro.

\section{REFERÊNCIAS}

ANVISA - Agência Nacional de Vigilância Sanitária. Portaria n.33/98. Disponível em: $<$ http://www. anvisa.gov.br/legis/portarias/33_98.htm>. Acesso em: 10 out. 2009.

AOAC - Association of Official Analytical Chemists. Official methods of analysis of the Association of the Analytical Chemists. $16^{\text {th }}$ ed. Washington, 1995.

AOAC - Association of Official Analytical Chemists. Official methods of analysis of the Association of the Analytical Chemists. $17^{\text {th }}$ ed. Virginia, 2000.

ASP, N.G.; AMELSVOORT, J.M.M. van; HAUTUAST, J.G.A. Euresta physiological implication of consumption of resistant starch in man. In: CONCLUDING, PLENARY MEETING OF EURESTA, 1994. Wageningen. Proceedings... p.87-94.

AWAD, M. Fisiologia pós-colheita de frutos. São Paulo: Nobel, 1993. 114p.

CAMPOS, J.M. O eterno plantio: um encontro com a natureza. São Paulo: Pensamentos, 1994. 250p.

CASTRO NETO, P.; SEDIYAMA, G.C.; VILELA, E.A. A probabilidade de ocorrência de períodos secos em Lavras, MG. Ciência e Prática, Lavras, v.4, n.1, p.46-45, 1980.

CORRÊA, A.D.; ABREU, C.M.P. de; SANTOS, C.D.; RIBEIRO, L.J. Determinação de alguns constituintes químicos de interesse nutricional da fruta-de-lobo (Solanum lycocarpum St. Hil.). Ciência e Agrotecnologia, Lavras, v.24, n.1, p.130$135,2000$.
CORRÊA, M.P. Dicionário de plantas úteis do Brasil e exóticas cultivadas. Brasília: Ministério da Agricultura/Instituto Brasileiro de Desenvolvimento Florestal, 1984. 6v.

DALL-AGNOL, R.; VON-POSER, G.L. The use of complex polysaccharides in the management of metabolic diseases: the case of Solanum lycocarpum fruits. Journal of Ethnopharmacology, Lousanne, v.71, n.1/2, p.337-341, 2000.

EERLINGEN, R.C.; DELCOUR, J.A. Formation, analysis, structure and properties of type III enzyme resistant starch. Journal of Cereal Science, London, v.22, n.2, p.129-138, 1995.

FRANCO, G. Tabela de composição química dos alimentos. 9.ed. São Paulo: Atheneu, 2005.307p.

FREITAS, M.C.J.; TAVARES, D. de Q. Caracterização do grânulo de amido de Bananas. Ciência e Tecnologia de Alimentos, Campinas, v.25, n.2, p.217-222, 2005.

FUKAGAMA, N.K.; ANDERSON, J.W.; HAGEMAN, G.; YOUNG, V.R.; MINAKER, K.L. Highcarbohidrate high fiber diets increase peripheral insulin sensitivity in health-young and old adults. American Journal of Clinic Nutrition, Bethesda, v.52, n.3,p.524, 1991.

GIUNTINI, E.B.; LAJOLO, F.M.; MENEZES, E.W. Potencial de fibras alimentares em países ibero-americanos: alimentos, produtos e resíduos. Archivos Latinoamericanos de Nutrición, Caracas, v.53, n.1, p.14-20, 2003.

GOMES, P. Fruticultura Brasileira. 13.ed. São Paulo: Nobel, 2007.446p.

GRASSELLI, C.S.M. Isolamento, caracterização físico-química e avaliação do efeito do polvilho do fruto da lobeira (Solanum lycocarpum St. Hil) na glicose e lipídeos sanguíneos. 2001.94 f. Tese (Doutorado em Tecnologia e Ciência dos Alimentos) - Universidade Federal de Viçosa, Viçosa, 2001.

HARDMAN, J.G.; MOLINOFF, P.B.; GILMAN, A.G. As bases famacológicas da terapêutica. 9. ed. Rio de Janeiro: McGraw Hill, 1996. 1436 p. 
HOEHNE, F.C. Frutas indígenas. São Paulo: Secretaria de Agricultura, Indústria e Comércio, 1946. 429p.

LAJOLO, F. M. ; SAURA-CALIXTO, F. ; WITTIG, E. ; MENEZES, E. W. Fibra dietética en Iberoamérica: tecnología y salud. obtención, caracterización, efecto fisiológico y aplicación en alimentos. São Paulo: Varela, 2001. v. 1, 469 p.

MARCIANO, S.C.; MAIA, F.J.; RESENDE, B.J.; BRUNORO, M.N. Uso do amido dos frutos da lobeira (Solanum lycocarpum St. Hil) por indivíduos diabéticos. Revista Brasileira de Nutrição Clínica, São Paulo, p.16, n.1, p.34-37, 2001

MOTTA, S.; GUERRA, M. de O.; PETERS, V.M.; REIS, J.E. de P. Administração de polvilho de lobeira (Solanum lycocarpum St. Hil) a ratas lactando: desenvolvimento físico a crias. Lecta, Bragança Paulista, v.2, n.1, p.53-60, 2002.

NELSON, D.L.; COX, M.M. Lehninger princípios de bioquímica. 3.ed. São Paulo: Sarvier, 2002.975 p.

OLIVEIRAJÚNIOR, E.N.; SANTOS, C.D.; ABREU, C.M.P de; CORRÊA, A.D.; SANTOS, J.Z.L. Alterações pós-colheita da "fruta-de-lobo" (Solanum lycocarpum St. Hil) durante o amadurecimento: análises físico-químicas, químicas e enzimáticas. Revista Brasileira de Fruticultura, Jaboticabal, v.26, n.3, p.410-413, 2004.

OLIVEIRA JUNIOR, E.N.; SANTOS, C.D.; ABREU, C.M.P.; CORRÊA, A.D.; SANTOS, J.Z.L. Análise nutricional da fruta-de-lobo (Solanum lycocarpum St. Hil) durante o amadurecimento. Ciência e Agrotecnologia, Lavras, v.27, n.4, p.846$851,2003$.
RANG, H.P.; DALE, M.M.; RITTER, J.M. Farmacologia. Rio de Janeiro: Guanabara Koogan, 2001. 702p

ROCHA, D.A. Caracterização físico-química e química do polvilho da fruta-de-lobo (Solanum lycocarpum St. Hil). 2006. 51 f. Dissertação (Mestrado em Agroquímica e Agrobioquímica) - Universidade Federal de Lavras, Lavras, 2006.

SILVA, M.M.; CORRÊA, A.D.; SANTOS, C.D.; ABREU, C.M.P de. Antinutrientes da fruta-delobo (Solanum lycocarpum St. Hil) em diferentes estágios de amadurecimento. In: CONGRESSO DE INICIAÇÃO CIENTÍFICA DA ESAL, 16., 2003, Lavras. Anais... Lavras: UFLA, 2003. p.229-231.

TINOCO, S.M.B. Importância dos ácidos graxos essenciais e os efeitos dos ácidos graxos trans do leite materno para o desenvolvimento fetal e neonatal. Cadernos de Saúde Pública, Rio de Janeiro, v.23, n.3, p.103-118, 2007.

VIEIRA JÚNIOR, G.; FERREIRA, P.M.; MATOS, L.G.; FERREIRA, E.C.; RODOVALDO, W.; FERRI, P.H.; FERREIRA, H.D.; COSTA, E.A. Anti-inflamatory effect of Solanum lycocarpum fruits. Phytotherapy Research, London, v.17, n.8, p.892-896, 2003.

VILELA, E.A.; RAMALHO, M.A.P. Análise das temperaturas e precipitações pluviométricas de Lavras, Minas Gerais. Ciência e Prática, Lavras, v.4, n.1, p.45-46, 1980 . 